\title{
A EXPERIÊNCIA DO PARTO A PARTIR DO OLHAR DE MÃES ADOLESCENTES
}

\section{THE EXPERIENCE OF DELIVERY ABOUT THE LOOKING OF TEACHING MOTHERS}

\author{
Wallquíria Morais Lima \\ Hisla Silva do Nascimento \\ Sanya Elayne Araújo Lima \\ Iolanda Gonçalves de Alencar Figueiredo
}

\begin{abstract}
RESUMO: O objetivo desse artgo é descrever a percepção de mães adolescentes acerca da experiência do parto. É um estudo descritivo e exploratório, com abordagem qualitativa, realizado em Hospital de referência do centro-sul piauiense com 8(oito) mães adolescentes, na faixa etária de 15 (quinze) a 18 (dezoito) anos. Os dados foram coletados entre novembro de 2014 a janeiro de 2015 através de entrevista semiestruturada e analisados com base na teoria de Mynaio. Atendeu as recomendações éticas da Resolução no 466 de 2012 e do Comitê de Ética em Pesquisa da Universidade Federal do Piauí com parecer $n^{\circ}$. 808.585. Quanto ao estado civil, 3 (três) das participantes declararam ser solteiras, 1 (uma) casada e 4 (quatro) em união estável. Referente ao nível de escolaridade, apenas 1(uma) referiu ter o ensino médio completo e 2(duas) disseram ter o ensino fundamental incompleto. Todas apontaram o parto como experiência dolorosa. Evidenciaram-se violações de direitos e violências obstétricas como o impedimento da entrada do acompanhante escolhido pela mulher; exames de toques sucessivos; episiotomia; retardamento do contato mãe-filho logo pós o parto; restrição hídrica e alimentar; posição litotômica e manobra de Kristeller. Solidão, preocupação com o bebê, desamparo, incapacidade de decidir sobre o seu corpo além da dor sumarizam sentimentos identificados no momento do parto. Envolvimento de gestores, financiando serviços adequados e humanizados à gravidez, parto e puerpério com qualificação dos profissionais de saúde, valorização o uso de práticas baseadas em evidências e educação e saúde podem representar um jeito positivo de assistir à mulher assegurando seus direitos e tornando-as protagonistas desse momento.
\end{abstract}

Palavras-chave: Adolescente. Obstetrícia. Parto Humanizado. Percepção. Violência.

ABSTRACT: The objective: To describe the perception of adolescent mothers about the experience of childbirth. Methodology: a descriptive and exploratory study, with a qualitative approach, carried out in a reference hospital in south-central Piauí, with 8 (eight) adolescent mothers, aged between 15 (fifteen) and 18 (eighteen) years. The data were collected between November 2014 and January 2015 through a semi-structured interview and analyzed based on Mynaio's theory. It met the ethical recommendations of Resolution 466 of 2012 and the Research Ethics Committee of the Federal University of Piauí with opinion no. 808,585. Results: Regarding the marital status, 3 (three) of the participants stated that they were single, 1 (one) married and 4 (four) in a stable union.

Educação, Psicologia e Interfaces, Volume 2, Número 1, p. 121-134, Janeiro/Abril, 2018 ISSN: $2594-5343$ https://doi.org/10.37444/issn-2594-5343.v2i1.55 
Regarding education level, only 1 (one) reported having completed high school and 2 (two) said they had incomplete elementary education. They all pointed to childbirth as a painful experience. Violations of rights and obstetric violence were evidenced as the impediment of the entrance of the companion chosen by the woman; tests of successive touches; episiotomy; retardation of mother-child contact soon after delivery; water and food restriction; lithotomic position and Kristeller maneuver. Solitude, worry about the baby, helplessness, inability to decide on your body beyond pain summarize feelings identified at the time of childbirth. Final considerations: Involving managers, financing adequate and humanized services to pregnancy, childbirth and the puerperium with qualification of health professionals, valuing the use of evidence-based practices, and education and health can be a positive way of assisting women in securing their rights and making them protagonists of that moment.

Keywords: Adolescent. Obstetrics. Humanized birth. Perception. Violence.

\section{INTRODUÇÃO}

A gravidez é classificada, segundo a Organização Mundial de Saúde (OMS), como gravidez na adolescência quando acontece em mulheres com faixa etária entre $10 \mathrm{e}$ 19 anos. A partir do momento em que a adolescente engravida, esta vivencia uma sobrecarga emocional intensa, requerendo, então, uma assistência diferenciada durante todo o ciclo gravídico e puerperal (GOMES el al, 2011).

Dentre outros, os impactos físicos e psicológicos sofridos por essas jovens no momento do parto são questões importantes, mas pouco tratadas nas literaturas pesquisadas que versam sobre a temática gravidez na adolescência. O trabalho de parto é tão importante quanto o pré-natal. É nesse momento onde toda ansiedade e medo carregado por toda gestação tornam-se realidade. Aqui, elas também precisarão do saber técnico-científico, mas necessitarão em demasia da paciência, sensibilidade e compreensão de todos os profissionais envolvidos.

O momento do parto há muito tempo deixou de ser um evento familiar para ser reconhecido por muitos como um evento hospitalar, onde procura-se controlar as complicações e situações de risco para o binômio mãe-filho (SOUSA et al, 2011).

E para que se chegue ao controle dessas complicações, práticas claramente prejudiciais e ineficazes como o uso de enteroclisma, tricotomia, infusão de soro com ocitocina, posição litotômica para o parto, restrição hídrica e alimentar são utilizadas,

Educação, Psicologia e Interfaces, Volume 2, Número 1, p. 121-134, Janeiro/Abril, 2018 ISSN: $2594-5343$ https://doi.org/10.37444/issn-2594-5343.v2i1.55 
(SILVA et al, 2013). Estas são as formas mais comuns de violência obstétrica no parto, de acordo com a Defensoria Pública do estado de São Paulo.

Segundo a Lei Orgânica sobre o Direito das Mulheres a uma Vida Livre da Violência, aprovada pela Assembleia Nacional da República Bolivariana da Venezuela, a violência obstétrica é toda conduta, ato ou omissão do profissional de saúde que, direta ou indiretamente, na esfera pública ou privada, afete o corpo e os processos reprodutivos das mulheres, expressada em um tratamento desumanizado, um abuso de medicalização e a patologização de processos naturais (GUERRA, 2008).

Ela pode ser classificada em Violência Obstétrica Física e Violência Obstétrica Psicológica. O primeiro caso acontece quando são realizados procedimentos invasivos e administração de medicamentos que não são necessários, já que o estado de saúde da mãe e do bebê se encontra estável, ou quando não for respeitado o tempo ou as possibilidades do nascimento biológico (CIELLO, 2012).

Acrescenta, ainda, que o tratamento desumanizado, a discriminação, a humilhação quando a mulher pede conselhos ou atenção durante o transcurso do parto, a omissão de informações sobre a evolução do nascimento e sobre o estado de seu bebê está inclusos no rol das Violências Obstétricas Psicológicas.

Gomes el al, (2011) defendem que durante o processo de parir, espaços devem ser criados para que a adolescente parturiente exerça sua autonomia, a entrada de um acompanhante de sua escolha deve ser permitida, todos os procedimentos devem ser informados e todos os seus direitos de cidadania devem ser respeitados. Porém, observase na prática, que o cuidado oferecido à jovem parturiente tem pouca ou nenhuma especificidade. Em alguns casos, há a desaprovação da maternidade nessa etapa da vida e os profissionais terminam por fazer uso de atitudes hostis (SANTOS el al, 2014).

Frente a esta problemática o presente estudo teve como objetivo descrever a percepção de mães adolescentes acerca do parto, provocando reflexões nos profissionais de saúde para consequências decorrentes de práticas assistenciais indevidas, sobre a vida dessas jovens, melhorando o planejamento e a assistência ao parto e, reduzindo com isso o impacto das representações negativas a ele associadas.

\section{MATERIAL E MÉTODO}


O presente estudo é do tipo exploratório e de cunho qualitativo uma vez que se aplica ao estudo da história, das relações, das representações, das crenças, das percepções e das opiniões, produto das interpretações que os humanos fazem a respeito de como vivem, constroem seus artefatos e a si mesmo, sentem e pensam como cita Mynaio, (2010)

Teve como cenário um hospital de referência do centro sul do piauiense que tem como missão prestar assistência integral a saúde de acordo com os princípios do SUS, nas diversas especialidades, nos níveis secundário e terciário aos seus usuários, conforme pactuações regionais, bem como contribuir para a formação de profissionais e da pesquisa.

Os sujeitos foram constituídos por mães adolescentes, de até 18 anos de idade, que tiveram seu parto realizado no hospital onde foi efetivada a pesquisa. Logo, constituíram amostra da pesquisa, 8 (oito) adolescentes puérperas que atenderam os seguintes critérios de inclusão: ser adolescente e encontrar-se no período de puerpério mediato no hospital onde foi efetivada a pesquisa, aceitar conversar com a pesquisadora sobre as práticas realizadas durante o seu parto e participar voluntariamente do estudo e assinar o Termo de Consentimento Livre e Esclarecido (TCLE) ou o Termo de Assentimento.

Os dados foram coletados no período de novembro de 2014 a janeiro de 2015 guiados por um instrumento do tipo entrevista semiestruturado constituído por duas partes: a primeira para caracterização das participantes quanto aos aspectos sociodemográficos (idade; estado civil; escolaridade; cidade; orientação quanto aos Direitos da Gestante e do Bebê, sobre qual profissional prestou essa orientação, e sobre alguma violência obstétrica que por ventura tenha sofrido durante o parto) a segunda contendo questões abetas norteadas pelas seguintes indagações: Poderia nos contar como foi sua experiência com o parto, a assistência prestada e as dificuldades vivenciadas durante esse momento?

Entrevista semiestruturada é aquela que possui tópicos ou questões amplas que precisam ser abordadas durante a entrevista. Assim, o entrevistador utiliza um guia de entrevista para garantir que todos os aspectos sejam contemplados, e deve encorajar as participantes a falarem livremente sobre todos os tópicos listados (POLIT; BECK, 2011). As entrevistas foram realizadas na Ala obstétrica do hospital onde estavam internadas as adolescentes em puerpério mediato e tiveram uma duração média de 25 (vinte e cinco) minutos, cada.

Educação, Psicologia e Interfaces, Volume 2, Número 1, p. 121-134, Janeiro/Abril, 2018 ISSN: 2594-5343 DOI: https://doi.org/10.37444/issn-2594-5343.v2i1.55 
Os dados objetivos foram organizados em tabela e analisados descritivamente e, os subjetivos transcritos, na íntegra, analisados a luz da literatura pertinente e distribuídos nas seguintes: I - "O saber de adolescentes puérperas acerca dos direitos da gestante e do bebê", II - "Violações de direitos e/ou violências obstétricas vivenciadas pelas adolescentes no momento do parto" e III - "Sentimentos e consequências manifestados pela experiência do parto". A identidade das participantes foi preservada tendo em vista a utilização de códigos (A-1, A-2) conforme amostra, assegurando dessa forma o sigilo do estudo

O estudo atendeu a todas as recomendações éticas da pesquisa envolvendo seres humanos, expressas na Resolução nº 466 de 2012 do Conselho Nacional de Saúde (CNS), obteve aprovação do Comitê de Ética em Pesquisa (CEP) da Universidade Federal do Piauí com parecer $\mathrm{n}^{\circ} .808 .585$.

\section{RESULTADOS E DISCUSSÃO}

O estudo contou com a participação de 8 (oito) adolescentes em puerpério mediato, das quais 3(três) tinha 15 (quinze) anos de idade, 2(duas) com dezessete e 3(três) com 18(dezoito) anos. Quanto ao estado civil, 3(três) delas declararam ser solteiras, 1(uma) casada e 4(quatro) em união estável. Em relação ao nível de escolaridade, apenas uma referiu ter o ensino médio completo e duas disseram ter o ensino fundamental incompleto.

Os dados do grupo estudado nos remetem aos descritos pelo Ministério da Saúde (2005), considerando que as adolescentes se encontram na fase de desenvolvimento, com mudanças biológicas, psicológicas e sociais ainda não bem estruturadas, entretanto a superposição da gestação e do parto acarreta uma sobrecarga física e psíquica, consequentemente, aumentando a vulnerabilidade aos agravos materno-fetais e psicossociais. Em relação ao nível de escolaridade, a maioria das jovens entrevistadas apresenta atraso escolar, haja vista que neste faixa etária já deveriam estar cursando o ensino médio. Sobre isso, estudos vêm mostrando que a correlação existente entre a escolaridade e fecundidade é uma realidade inversamente proporcional.

\section{Categoria I: $O$ saber de adolescentes puérperas acerca dos direitos da gestante e do bebê}


Infelizmente, muitos dos direitos da mulher na hora do parto e pós-parto são desrespeitados. Estes, na maioria das vezes, não são reivindicados por falta de conhecimento da própria mãe.

São direitos básicos da gestante durante a internação e o trabalho de parto, de acordo com a UNICEF (2011): acesso a atendimento digno e de qualidade; assistência ao parto realizada de forma humanizada e segura; ser escutada e ter as suas dúvidas esclarecidas; expressar os seus sentimentos e suas reações livremente; escolher a melhor posição durante o trabalho de parto e parto e ter um acompanhante de suas escolhas durante o trabalho de parto, parto e pós-parto.

Buscou-se, então, saber das puérperas adolescentes se elas conheciam ou não seus direitos e os direitos de seus bebês. Apenas 2(duas) duas relataram terem sido orientadas quanto a esse assunto, mas não sabiam de um direito básico, como é o caso da presença de um acompanhante de sua livre escolha no momento do parto, como podemos ver em suas falas a seguir:

\footnotetext{
"A enfermeira que me falou desses direitos, mas ela não me disse que eu podia escolher alguém pra entrar comigo." (A-2l)

"Eu ouvi falar disso quando ia pro postinho fazer o pré-natal. Aí, [enfermeira] me falou do Bolsa Família e outras coisas, mas não lembro dela ter falado que minha mãe podia entrar pra ver meu parto." (A-3)
}

Segundo Enderle et al (2012), quando as adolescentes não são orientadas quanto aos Direitos da Gestante e do Bebê, seu poder de reivindicação e argumentação é diminuído, mesmo com a lei assegurando essa prerrogativa. Os resultados deste estudo nos mostram como as participantes não sabiam da existência da Lei 11.108/2005 e do Estatuto da Criança e do Adolescente, documentos que garantem o direito de serem acompanhadas por alguém de sua escolha, não exigiram o cumprimento destes amparos legais.

Pode-se perceber também, no discurso dos sujeitos, que o profissional informante foi a enfermeira, durante as consultas de pré-natal. Destaca-se a importância, então, do enfermeiro como propagador de informações. Ressalta-se, entretanto, a necessidade dessa classe incluir em suas rotinas de pré-natal o diálogo com as gestantes sobre os Direitos da Gestante e do Bebê. 
Para Progiante e Costa (2012) as práticas educativas desenvolvidas pelas enfermeiras no campo obstétrico são um instrumento de suas ações de cuidado que podem transformar a maneira de parir e nascer em confluência com a Política Nacional de Atenção Integral à Saúde da Mulher, que enfatiza que a humanização da atenção em saúde envolve "compartilhar saberes" e "reconhecer direitos".

\section{Categoria II: Violações de direitos e violências obstétricas vivenciadas pelas puérperas adolescentes no momento do parto}

Foram identificadas, a partir das entrevistas realizadas, 7(sete) tipos de violências obstétricas que aconteceram durante o parto, a saber: impedimento da entrada do acompanhante escolhido pela mulher; exames de toques sucessivos; episiotomia; retardamento do contato do bebê com a mulher logo após o parto; restrição hídrica e alimentar; posição litotômica e manobra de Kristeller.

Embora a permissão da entrada de um acompanhante seja um dos aspectos mais fáceis de ser implementado em termos de custos e adequação da estrutura física, essa foi uma violação de direitos encontrada em todas as entrevistadas que relataram não terem a presença de um acompanhante de sua escolha no momento do parto.

"Eu queria que mãe tivesse comigo. Acho que era melhor se fosse assim, se ela tivesse entrado comigo. Eu me senti sozinha lá dentro." (A-3)

"Eu passei mal, vomitei. Queria que minha mãe tivesse comigo." (A-2) "Não. Ninguém entrou comigo [...]'tava' só eu, o doutor e as enfermeiras." (A-4)

As mulheres que, durante o trabalho de parto, recebem apoio contínuo têm mais chances de não serem submetidas à cesariana e de terem um parto normal sem uso de analgesia; de terem tempo de trabalho de parto reduzido; menor insatisfação com a experiência do processo de nascimento e um recém-nascido com melhores índices de Apgar nos primeiros cinco minutos de vida, reforça (FRUTUOSO, 2013).

Os cuidados com o recém-nascido normal/baixo risco, logo após o nascimento, devem se resumir em enxugar, aquecer, avaliar e entregá-lo à mãe (BRASIL, 2003). No presente estudo constatou-se que o referido hospital não seguia essa recomendação, pois apenas 1(uma) das entrevistadas relatou ter conhecido seu bebê logo após o parto, fazendo

Educação, Psicologia e Interfaces, Volume 2, Número 1, p. 121-134, Janeiro/Abril, 2018 ISSN: 2594-5343 DOI: https://doi.org/10.37444/issn-2594-5343.v2i1.55 
com que o retardamento do contato do bebê com a mulher logo após o parto fosse a segunda violência mais citada.

\begin{abstract}
"Só soube que meu bebê 'tava' bem quando cheguei aqui [alojamento conjunto]. Não vi ele [o bebê] lá [Centro Cirúrgico].” (A-6)

"Só conheci meu bebezinho quando vim pra cá [alojamento conjunto], porque minha sogra me mostrou." (A-1)
\end{abstract}

Para Matos et al, (2010) a realização do contato pele-a-pele precoce mãe-filho transmite para a mãe tranquilidade e segurança, pois neste momento ela pode sentir, ver, segurar o seu bebê, e toda a ansiedade e curiosidade pode ser sanada. Da mesma forma é importante que o recém-nascido normal esteja em contato com a mãe logo após o nascimento, estabelecendo, assim, a formação do vínculo (GOMES el al, 2011).

Em relação à restrição hídrica e alimentar, todas as adolescentes referiram não ter realizado nenhuma ingesta durante o trabalho de parto, inclusive a puérpera que teve seu bebê por via vaginal. 'Não, ninguém perguntou se eu 'tava' com fome ou se eu queria beber água. Até eu ter o menino não comi nada." (A-5)

O jejum obrigatório pode causar em mulheres que estão em trabalho de parto uma progressão insatisfatória. O dispêndio de energia durante o processo de parturição é equivalente ao do exercício físico moderado contínuo, ressalta (WEI et al, 2011).

Costa et al, (2011) reforçam recomendações de uso restrito da episiotomia pela Organização Mundial de Saúde, pois quando realizada de forma rotineira e liberal é classificada pela OMS como prática claramente prejudicial, devendo, portanto ser desestimulada e indicada somente em casos necessários. "Só senti a dor na hora, ninguém avisou que iam fazer isso [episiotomia] comigo. Doeu muito, ainda hoje dói.” (A-7)

$\mathrm{Na}$ fala descrita acima de uma das puérperas que passou pela episiotomia nota-se a dor sentida pela mesma no momento da realização do procedimento. Pode-se perceber que o procedimento não foi informado antes de sua realização.

No Brasil, de acordo com Ciello (2012), a episiotomia é a única cirurgia realizada sem o consentimento da paciente e sem que ela seja informada sobre sua necessidade, seus riscos, seus possíveis benefícios e efeitos adversos. A assistência obstétrica centrada nas necessidades da cliente é caracterizada pelo direito à autonomia da parturiente. Esta, quando informada sobre os procedimentos que serão realizados, tem liberdade de escolha ou recusa a qualquer procedimento relacionado a seu corpo (BARBOSA, 2013). 
Aqui, a episiotomia poderia ter sido evitada se a posição adotada para que a adolescente desse a luz à criança fosse diferente da litotômica, posição rotineiramente utilizada em partos normais no hospital de referência onde foi realizada pesquisa. "Só me mandaram deitar lá[...] e colocar as 'perna' naquele negócio!” (A-7)

No estudo de Barbosa (2013) ficou evidente que a escolha da posição vertical nos partos, pelas parturientes, resultou em um menor índice de episiotomia. A maioria das lacerações perineais, quando ocorreram, foi de primeiro grau e o índice de Apgar sempre superior a sete no primeiro e quinto minuto.

O exame de toques sucessivos também foi apontado no estudo. Esse procedimento deve ser realizado apenas por profissionais da saúde treinados, com mãos limpas e usando luvas estéreis. A quantidade de vezes que o toque deve realizado tem que ser limitado ao estritamente necessário, postula a OMS (2014) sendo, portanto, durante o primeiro estágio do parto, um toque a cada 4 horas é suficiente. "Não gostei desse monte de toque. A pessoa tá sentindo um monte de dor e ficam fazendo esses toques toda hora..." (A-8)

O Manual de Procedimentos da Norma Oficial para a Atenção Integral da Saúde Sexual e Reprodutiva estabelece que o exame de toque deva ser realizado a cada 4 horas. É difícil estabelecer um número considerado "ideal” e alcançar o mínimo possível os inconvenientes, principalmente em hospitais onde são realizados estágios de cursos de graduação e pós-graduação (TERÁN et al. 2013).

Além dos exames de toque sucessivos, a parturiente que teve seu parto por via vaginal também relatou que uma das profissionais realizou a manobra de Kristeller. “[...] e ainda a mulher subiu aqui [fundo do útero] pra eu ter o menino. 'Encarcou' aí foi que doeu mesmo..." (A-7)

Em várias partes do Brasil há relatos de procedimentos que aceleram o período expulsivo, entre eles a manobra de Kristeller. Essa prática é reconhecidamente danosa à saúde e, ao mesmo tempo, ineficaz, causando à parturiente o desconforto da dor provocada e também o trauma que se seguirá indefinidamente. São complicações da prática desse procedimento: trauma das vísceras abdominais, do útero e descolamento da placenta (CIELLO, 2012).

\section{Categoria III: Sentimento e consequências manifestados pela experiência do parto}


Nos últimos anos, em nosso país, houve um crescente desestímulo ao parto normal, este influenciado pela cultura de cesariana, associada, na maioria das vezes, ao parto sem dor. Esse desestímulo, por vezes, parte até das próprias mulheres que não tiveram uma experiência tão boa em um parto normal, como podemos observar abaixo no discurso de uma das entrevistadas: "Eu não queria parto normal... Depois disso tudo que sofri, agora que não quero mais parto normal. Não quero ter mais filhos. Não mais quero passar pelo que passei." (A-7)

No parto vaginal, segundo Barbosa (2013), a violência da imposição de rotinas, da posição de parto e das interferências obstétricas desnecessárias complicam e inibem o desencadeamento natural dos mecanismos fisiológicos do parto. Assim, este passa a ser sinônimo de patologia e de intervenção médica, tornando uma experiência de terror, impotência, alienação e dor. Logo, não é surpreendente a introjeção da cesárea, pelas mulheres, como melhor forma de se ter um filho, sem medo, sem risco e sem dor.

Ademais, pôde-se perceber um misto de sentimentos, vivenciados pelas adolescentes durante o parto. A solidão, preocupação como estado de saúde do bebê, impotência e despreparo, incapacidade de decidir sobre seu corpo além da dor, sumarizam alguns deles, como mostra os depoimentos que segue:

\footnotetext{
"Eu queria que mãe tivesse comigo. Acho que era melhor se fosse assim, se ela tivesse entrado comigo. Eu me senti sozinha lá dentro." (A-3)

"Só soube que meu bebê 'tava' bem quando cheguei aqui [alojamento conjunto]. Não vi ele [o bebê] lá [Centro Cirúrgico].” (A-4)

"Não, ninguém perguntou se eu 'tava' com fome ou se eu queria beber água. Até eu ter o menino não comi nada." (A-5)

"Só senti a dor na hora, ninguém avisou que iam fazer isso [episiotomia] comigo. Doeu muito, ainda hoje dói." (A-7)

"Só me mandaram deitar lá na hora e colocar as 'perna' naquele negócio! (A-7)

"Não gostei desse monte de toque [..] pessoa tá sentindo um monte de dor e ficam fazendo esses toques toda hora (A-8)
}

Para Ciello (2012) o parto e o nascimento de um filho são eventos marcantes na vida de uma mulher. Mas, infelizmente, são lembrados muitas vezes como uma experiência traumática, sendo a dor do parto, na maioria das vezes, é relatada como a dor da solidão, da humilhação e da agressão, com práticas institucionais e dos profissionais de saúde que criam ou reforçam sentimentos de incapacidade, inadequação e impotência da mulher e de seu corpo. $\mathrm{O}$ autor chama a atenção para os benefícios que a presença do 
acompanhante pode trazer à mulher (sentimento de confiança, controle e comunicação; menores taxas de dor, pânico e exaustão; diminuição do sentimento de ansiedade, de solidão e de preocupação com o estado de saúde do bebê e maior satisfação) nesse momento tão importante de sua vida.

Percebe-se, portanto, que a presença de um acompanhante durante o trabalho de parto poderia ter diminuído ou até evitado os sentimentos de solidão, de preocupação com estado de saúde do bebê e de desamparo percebidos nos discursos dessas jovens. Tornando, assim, mais prazeroso e humanizado o momento do parto.

Já o sentimento de dor poderia ter sido diminuído se não tivessem sido realizados tantos toques vaginais como foi relatado pela adolescente. A mesma não pôde decidir, no momento do parto, qual a posição para ter seu filho, foi-lhe imposta a litotomia. Mas, às mulheres, durante um parto normal, deve ser dado o livre arbítrio para a escolha da posição que lhe deixe mais confortável e reduza o nível de dores.

\section{CONSIDERAÇÕES FINAIS}

O estudo buscou conhecer a percepção de mães adolescentes sobre a experiência do parto e, identificou situações de violações de direitos e violências obstétricas que acontecem no cenário da pesquisa.

A realidade do Centro Cirúrgico e Obstétrico precisa ser repensada e algumas mudanças implementadas. Considerando que o trabalho de parto e parto é um momento único na vida da mulher/adolescente, estes requerem um ambiente mais acolhedor, que incentive mais os partos normais, a deambulação, a adoção de posições mais confortáveis para a mulher no momento do parto, a permissão da entrada de um acompanhante escolhido pela parturiente, o contato precoce da mãe com o bebê e, principalmente, o respeito pela fisiologia do parto.

Outro aspecto importante que deve ser frisado é em relação aos direitos básicos de toda gestante, como o direito a um acompanhante, de ser informada quanto aos procedimentos que serão realizados e de se negar a aceitá-los. Enfim, muitas mulheres, principalmente as adolescentes, não são informadas quanto às Leis que as protegem e acabam por aceitar e não contestar algumas práticas que, na verdade, as violam. Nesse pensar, cabe ao enfermeiro, durante as consultas de pré-natal, esclarece-las e encorajálas.

Educação, Psicologia e Interfaces, Volume 2, Número 1, p. 121-134, Janeiro/Abril, 2018 
Há, portanto, como mudar o cenário atual do parto no Brasil. Basta um comprometimento real dos gestores, financiando serviços mais adequados e humanizados para o atendimento das puérperas; profissionais de saúde cada vez mais qualificados e especializados em Obstetrícia, fazendo cada vez mais o uso de práticas baseadas em evidências e mulheres mais orientadas em relação aos seus direitos durante a gestação, cobrando dos gestores e profissionais um cuidado humanizado que não faça uso de procedimentos que se configurem como violências obstétricas.

\section{REFERÊNCIAS BIBLIOGRÁFICAS}

Assistência ao parto normal: um guia prático da OMS Disponível em:

<http://abenfo.redesindical.com.br/arqs/materia/56_a.pdf>. Acesso em: 22/07/2014.

BRASIL. Lei $\mathbf{n}^{\mathbf{0}} \mathbf{1 1 . 1 0 8}$, de 7 de abril de 2005.

. Ministério da Saúde. Parto, aborto e puerpério: assistência humanizada à saúde. 2005. 202 p.

Conselho Nacional de Saúde. Resolução No 466 de 12 de dezembro de 2012.

BARBOSA TA. Percepção das puérperas frente ao cuidado das enfermeiras obstetras no parto e nascimento. 2013. 66 f. Trabalho de Conclusão de Curso (Graduação) Faculdade de Enfermagem, Universidade de Brasília, Ceilândia, 2013.

CIELLO C, CARVALHO C, KONDO C, DILAGE D, NIY D, WERNER L, et al. Violência Obstétrica "Parirás com dor". Dossiê elaborado pela Rede Parto do Princípio para a CPMI da Violência Contra as Mulheres, 2012.

COSTA NM, OLIVEIRA LC, SOLANO LC, MARTINS PHMC, BORGES IF. Episiotomia nos partos normais: uma revisão de literatura. Facene/Famene. 2011; 9(2): 45-50.

ENDERLE, C.F.; KERBER, N.P.C.; SUSIN, L.R.O.; MENDOZA-SASSI, R.A. Avaliação da atenção ao parto por adolescentes em um hospital universitário. Rev Bras Saúde Mater Infant. Recife, v.12, n.4, p.383-394, 2012.

FRUTUOSO LD, BRÜGGEMANN OM. Conhecimento sobre a lei 11.108/2005 e a experiência dos acompanhantes junto á mulher no centro obstétrico. Texto Contexto Enferm. 2013; 22(4): 909-17.

GOMES VLO, FONSECA AD, ROBALLO EC. Representações sociais de adolescentes mães acerca do momento do parto. Esc. Anna Nery. 2011; 25 (2); 300-05. 
GUERRA GB. Editorial Violência Obstétrica. Revista de la Facultad de Medicina. 2008; 31(1): 5-6.

MATOS TA, SOUZA MS, SANTOS EKA, VELHO MB, SEIBERT ERC, MARTINS

NM. Contato precoce pele a pele entra mãe e filho: significado para mães e contribuições para a enfermagem. Rev Bras Enferm. 2010; 63(6): 998-1004.

MINAYO MCS. O desafio do conhecimento: pesquisa qualitativa em saúde. $11^{\text {a }}$ ed. São Paulo: Hucitec, 2008.

POLIT, D. F.; BECK, C. T. Fundamentos de pesquisa em enfermagem: avaliação de evidências para a prática da enfermagem. $7^{\mathrm{a}}$ ed. Porto Alegre: Artmed. p. 669, 2011

PROGIANTI, J.M.; COSTA, R.F. Práticas educativas desenvolvidas por enfermeiras: repercussões sobre vivências de mulheres na gestação e no parto. Rev Bras Enferm. Brasília, v.65, n.2, p. 257-263, 2012.

SANTOS NCP, VOGT SE, PIMENTA AM, DUARTE ED, MADEIRA LM, ABREU MNS, et al. Resultados maternos e neonatais no trabalho de parto e parto de adolescentes admitidas em um Centro de Parto Normal brasileiro. Adolesc Saúde. 2014; 11(3): 39-50.

SOUZA TG, GAIVA MAM, MODES PSSA. A humanização do nascimento: percepção dos profissionais de saúde que atuam na atenção ao parto. Rev. Gaúcha Enferm. 2011; 32 (3): 479-86

SILVA RC, SOARES MC, JARDIM VMR, KERBER NPC, MEINCKE SMK. O discurso e a prática do parto humanizado de adolescentes. Texto Contexto Enferm. 2013; 22(3): 629-36.

UNICEF. Guia dos Direitos da Gestante e do Bebê. São Paulo: Globo, 2011.

Violência Obstétrica: você sabe o que é? disponível em:

<http:www.defensoria.sp.gov.br/dpesp/repositório/41/violência\%20obstetrica.pdf>. Acesso em: 19/10/2014.

TERÁN P, CASTELLANOS C, BLANCO MG, RAMOS O. Violência obstétrica: percepción de las usuárias. Ver Obstet Ginacol Venz. 2013; 73 (3): 171-80.

WEI CY, GUALDA DMR, SANTOS POJ. Movimentação e dieta durante o trabalho de parto: a percepção de um grupo de puérperas. Texto Contexto Enferm. 2011; 20 (4): $717-25$.

\section{Credenciais do/as autor/as}


LIMA, Wallquíria Morais. Enfermeira. Residente em enfermagem obstétrica pela Escola de Saúde Pública de Fortaleza/CE. Enfermeira da Estratégia de Saúde da Família.

Fortaleza/CE, Brasil. E-mail: lima.wm@hotmail.com

NASCIMENTO, Hisla Silva do. Bacharel Em Enfermagem Pela Universidade Federal Do Piauí, Picos/PI, Brasil. Enfermeira Assistencial no Hospital Regional. Picos/PI, Brasil. E-mail: hisla.nascimento@ hotmail.com

LIMA, Sanya Elayne Araújo.Enfermeira da Estratégia de Saúde da Família,

Coordenadora Municipal das ações de saúde da criança e do adolescente. Picos/PI, Brasil. E-mail: sanyaelayne@hotmail.com

FIGUEIREDO, Iolanda Gonçalves de Alencar. Enfermeira. Mestre em Terapia intensiva pelo Instituto Brasileiro de Terapia Intensiva- IBRATI. Docente do Curso de Enfermagem da Universidade Federal do Piauí, CSHNB, Picos/PI, Brasil. E-mail: iolandalencar2009@ hotmail.com

Endereço para correspondência: Iolanda Gonçalves de Alencar Figueiredo, Rua Santa Rita, 1699, Bairro Canto da várzea. CEP 64600-144, Picos/PI. E-mail:

Iolandalencar2009@hotmail.com

Como citar este artigo (Formato ABNT): LIMA, Wallquíria Morais et al.. A experiência do parto a partir do olhar de mães adolescentes. Educação, Psicologia e Interfaces, v. 2, n.1, 121-134, 2018. DOI: https://doi.org/10.37444/issn-25945343.v2i1.55

Recebido: 01/02/2018.

Aceito: 26/03/2018. 